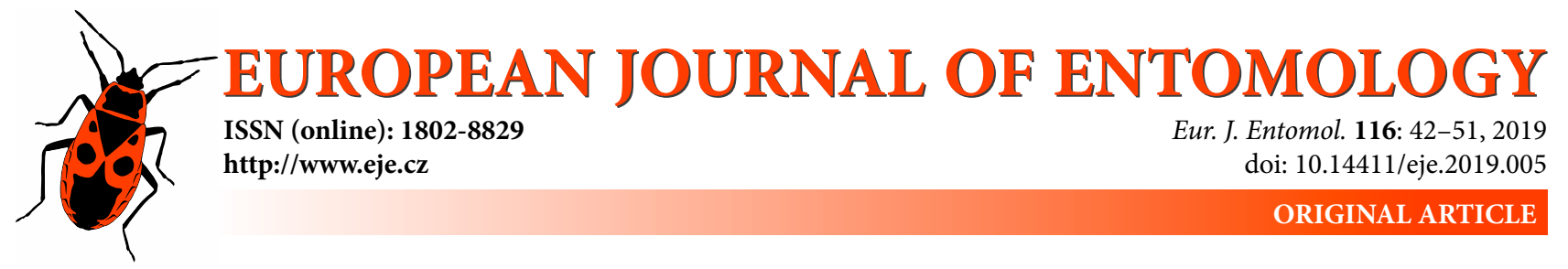

\title{
One step closer to understanding the ecology of Cameraria ohridella (Lepidoptera: Gracillariidae): The effects of light conditions
}

\author{
RadosŁaW JAGIEŁŁO ${ }^{1}$, Edward BARANIAK ${ }^{2}$, Marzenna GUZICKA ${ }^{1}$, PIOtr KAROLEWSKI ${ }^{1}$, Adrian KUKOWSKI $^{1,3}$ \\ and MARIAN JĘDRZEJ GIERTYCH ${ }^{1,4}$ \\ ${ }^{1}$ Polish Academy of Sciences, Institute of Dendrology, Parkowa 5, 62-035, Kórnik, Poland; e-mail: rjagiello@man.poznan.pl, \\ guzicka@man.poznan.pl, pkarolew@man.poznan.pl, adrian.lukowski@gmail.com, giertych@man.poznan.pl \\ ${ }^{2}$ Adam Mickiewicz University, Faculty of Biology, Umultowska 89, 60-995, Poznań, Poland; e-mail: baraniak@amu.edu.pl \\ ${ }^{3}$ Poznań University of Life Sciences, Faculty of Forestry, Wojska Polskiego 28, 60-637, Poznań, Poland \\ ${ }^{4}$ University of Zielona Góra, Faculty of Biological Sciences, Szafrana 1, 65-516, Zielona Góra, Poland
}

Key words. Lepidoptera, Gracillariidae, Cameraria ohridella, Aesculus hippocastanum, light conditions, herbivore, leaf-miner, oocytes, phenolics oxidative capacity, plant-insect interactions

\begin{abstract}
Horse chestnut leaf miner (Cameraria ohridella) has achieved ecological success by colonizing the entire European range of its primary host, horse chestnut (Aesculus hippocastanum). This insect has attracted the attention of scientists, but its ecology is poorly understood. Here, we investigated the effects of varying degrees of light availability on the leaf morphology of horse chestnut saplings and the performance of $C$. ohridella. A pot experiment under greenhouse conditions was performed in which the photosynthetic photon flux density (PPFD) was reduced from full light by $50 \%$ (high light $-\mathrm{HL}$ ) or $80 \%$ (low light - LL). Insect performance parameters were quantified (i.e., pupal mass, efficiency of conversion of utilised leaf tissue (ECU) and potential fecundity). Compared with HL leaflets those from LL were characterised by higher contents of nitrogen and water but lower total phenolics. The oxidative capacity of phenolics (at $\mathrm{pH} \approx 10$, common in the lepidopteran gut) was low and did not differ in the two treatments. Compared with those collected from HL leaves, the mines of those collected from leaves of plants grown under LL conditions were larger in area but the leaf mass utilized by larvae was similar. Pupae were heavier in LL than in HL conditions, and ECU was higher in LL. The potential fecundity of females was not sensitive for experimental treatment. We conclude that (1) reduced light had a strong beneficial effect on the performance of $C$. ohridella and (2) phenolics in $A$. hippocastanum leaf tissues are a poor defence against this herbivore.
\end{abstract}

\section{INTRODUCTION}

Miners are recorded in four orders of Insecta, in particular in species belonging to Diptera and Lepidoptera and fewer belonging to Coleoptera and Hymenoptera (Hering, 1951). Leaf miners have a characteristic method of obtaining food: they consume leaf tissue from the inside leaving the outer leaf structure intact. Compared with externalfeeding insects, this way of obtaining food has many benefits, such as protection against diseases and UV radiation and relatively constant hydrothermal conditions (Sinclair $\&$ Hughes, 2010). However, leaf-mining species are frequently parasitized and at high risk of being attacked by predators because their larvae are not very mobile (Connor \& Taverner, 1997).

Horse chestnut leaf miner, Cameraria ohridella Deschka \& Dimić (Lepidoptera: Gracillariidae), which was first described in Macedonia near Lake Ohrid (Deschka \& Dimić, 1986), is an example of a highly successful leaf miner. This species colonized almost all of Europe within a short pe- riod of time (Šefrová \& Laštůvka, 2001). The range of $C$. ohridella continues to expand; in 2003, it reached southern Sweden (Rämert et al., 2011), and a recent report indicates that this insect is in Kazakhstan (Gninenko et al., 2017). Its main host, horse chestnut Aesculus hippocastanum L., was introduced into central Europe in XVI c. (Ravazzi \& Caudullo, 2016). Currently, trees of this species are common throughout the continent. They occur in both urban and rural environments and are commonly planted in lines or alleys. This species has high decorative value, especially during the flowering period, and its chestnuts that fall to the ground attract the attention of children and, as described by Gwiazdowicz \& Wiśniewski (2011) are also of interest to senior citizens. Escin, the mixture of triterpenoid saponins found in the tissues of A. hippocastanum, is used to treat chronic venous insufficiency, haemorrhoids and post-operative oedema (Sirtori, 2001). Escin also exhibits anti-cancer effects (Cheong et al., 2018). Fujimura et al. 
(2006) suggest that extracts of $A$. hippocastanum may have anti-aging effects as they induce fibroblasts to contract.

Controlling $C$. ohridella via conventional chemical methods involving the spraying of leaves is effective (Percival et al., 2012) but difficult to implement in urban areas. One alternative is to introduce imidacloprid into the vascular system of the trees (Ferracini \& Alma, 2008), which may have long-lasting effects on $A$. hippocastanum (Jagiełło et al., 2019). This year, the European Commission has banned the outdoor use of imidacloprid (European Commission, 2018) in light of the risk to pollinators. It seems that the simplest and earliest-devised method of control, i.e., the removal of leaf litter containing diapausing pupae (Deschka, 1993), is relatively effective and environmental friendly when properly and systematically applied (Kehrli \& Bacher, 2003). Regarding natural biocontrol, C. ohridella is mainly parasitized by local polyphagous parasites (Volter \& Kenis, 2006, Ferracini \& Alma, 2007). No specialist parasites of this species are currently known. Polyphagous parasitoids are ineffective in controlling this herbivore. Kenis et al. (2005) conclude that only monophagous parasitoids are likely to inhibit outbreaks, because their life cycles are closely related to those of their hosts. Studying the biology and ecology of $C$. ohridella, especially its ecological niche, may lead to the development of appropriate biological or more complex methods for limiting its negative effect on $A$. hippocastanum and the closely related (and highly susceptible) Aesculus turbinata Blume. Moreover, there are many other potential host plants at risk of being attacked by this pest (Péré et al., 2010; D'Costa et al., 2013, 2014; Walczak et al., 2017).

Within the crowns of mature trees there are parts that are shaded and others that are exposed to the sun, which create different life conditions for organisms. There are substantial differences in morphology and biochemistry of the leaves growing in these different light conditions. Leaf mass per area (LMA) is a good indicator of leaf structure, as it incorporates leaf mass and leaf area into one value. Analyses conducted by Poorter et al. (2009) indicate a positive correlation between LMA and daily photon irradiance. Regarding biochemistry, plants exposed to low light intensities have lower levels of secondary metabolites that provide a defence against unfavourable abiotic ( $\mathrm{Li}$ et al., 1993) and biotic factors (Koricheva, 2002; Bidart-Bouzat $\&$ Imeh-Nathaniel, 2008). Among the broad spectrum of secondary metabolites, phenolics are a rich group of compounds found in plant tissues that play a multitude of roles. They may have antioxidant properties, chelate heavy-metal ions, exhibit antifungal and antibiotic activity or repel (especially in the case of tannins) herbivores by changing the taste of plant tissues and/or binding and denaturing proteins (Kulbat, 2016). D'Costa et al. (2014) compared the leaf traits of five Aesculus taxa and found that the level of total phenolics is not directly associated with their susceptibility to $C$. ohridella. Within the phenolic compounds, hydrolysable tannins are thought to act as deterrents and so reduce the digestion of plant tissues, especially of deciduous woody species. The discussion about the role of tan- nins in insect diet started with the work of Feeny (1970). Aside from classic detrimental effect of tannins on protein binding, those in the leaves induce insect mid gut lesions and inhibit feeding (Schoonhoven et al., 2012). The antiherbivory roles of phenolic compounds were considered by Salminen \& Karonen (2011), who emphasises the role of the oxidative capacity of tannins. These findings and those of Oszmiański et al. (2014) and Jagiełło et al. (2017) indicate that high contents of condensed tannins in the leaves of $A$. hippocastanum may not have a negative effect on the development of $C$. ohridella. On the other hand, Ferracini et al. (2010) indicate that the saponins present in leaves of the HBT genotype of Aesculus pavia L. adversely affect the development of $C$. ohridella and these saponins are not present in the leaves of $A$. hippocastanum.

The nitrogen content of leaves depends on the light conditions (Lambers et al., 2008). Among the hypotheses considered by Galway et al. (2004), the "plant vigour hypothesis" is consistent with the general pattern that leaf miners perform best when feeding on non-stressed plants. Increased moisture or soil nitrogen can indirectly improve leaf miner performance, but there is no information on their relationship with light levels. However, research on the performance of Cameraria hamadryadella Clemens (Lepidoptera: Gracillariidae), an oligophagic (host plants: Quercus spp.) North American species, indicates it survives better on shaded plants than on those exposed to full sun (Connor, 2006).

Horse chestnut leaf miner is a well-studied species. (A Scopus search of "Cameraria ohridella" within "article title, abstracts and keywords" yielded 181 results on September 19, 2018). Although several aspects of $C$. ohridella have been investigated, its interaction with abiotic factors are little studied. Its performance on leaves growing under different light conditions was investigated by Birner \& Bohlander (2004), who show that a longer time period was required for mine development on sun-exposed leaves than on shaded leaves and this was associated with smaller mines and longer developmental times. The effects of exposure to sun were also investigated by Tarwacki et al. (2012), who report greater parasitism of $C$. ohridella in leaves exposed to sun. However, the direct effects of light conditions on the phytochemistry of $A$. hippocastanum leaves and the associated indirect effects on $C$. ohridella performance are poorly known. To fill these gaps in our knowledge of the ecology of $C$. ohridella we studied its performance under different light conditions and its association with the morphology and a few chemical measures of its host's leaves. Based on the results of Birner \& Bohlander (2004), we expected the area of leaf mines that develop on leaves under low light (LL) conditions to be greater than those that developed under high light (HL) conditions. Assuming that leaves of plants under LL will be characterized by lower LMAs, we hypothesized that the amount of leaf tissue utilised by insects is independent of light conditions. In addition, we tested the hypothesis that the food quality of LL leaves is better than that of HL leaves due to their higher contents of nitrogen, bound largely in amino acids 
and proteins, and lower contents of phenolic compounds, which may result in its better performance under LL conditions. Adopting the approach proposed by Salminen \& Karonen (2011), we investigated the influence of light conditions on the oxidative capacity of phenolic compounds in an alkaline environment corresponding to that of the lepidopteran gut.

\section{MATERIALS AND METHODS}

\section{Study design}

A pot experiment with horse chestnut (A. hippocastanum) saplings was conducted beginning in the spring of 2016. Two greenhouses, located in the grounds of the Institute of Dendrology $\left(52^{\circ} 14^{\prime} 40.8^{\prime \prime} \mathrm{N}, 17^{\circ} 06^{\prime} 01.8^{\prime \prime} \mathrm{E}\right)$, covered with foil with a UV filter were used. Each greenhouse was divided into two with different light-conditions: one was additionally shaded with mesh (low light - LL) and one with only the foil covering (high light - HL). Eight measurements of the photosynthetic photon flux density

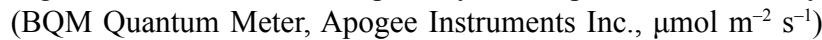
in each of the two light-conditions were taken on a cloudy day in order to quantify the differences in the two light conditions. The measurements are relative to full-light conditions. In each of the greenhouse compartments a temperature sensor $\left(\mathrm{HOBO}{ }^{\circledR}\right.$ Pro v2 U23-001, Onset Computer Corporation; $\mathrm{n}=4$ ) connected to a data logger was fixed at a height of $0.5 \mathrm{~m}$. The sensors recorded temperature $\left( \pm 0.1^{\circ} \mathrm{C}\right)$ every hour. One-year-old saplings (obtained from the Piaski Forest District Nursery, State Forests National Forest Holding, Poland) were planted in pots (15 $\mathrm{dm}^{3}$ volume) filled with sieved soil (obtained from a compost heap) previously mixed with peat $(\mathrm{pH} \approx 7.0)$ in a $\mathrm{v} / \mathrm{v}$ ratio of $7: 3$ soil : peat. Nine plants were placed in each compartment of each greenhouse (36 in total), and drip irrigation systems were installed. The plants were watered as necessary, and weeds were removed systematically. Before the emergence of the overwintering generation of C. ohridella, the leaf litter from a neighbouring (ca. $2 \mathrm{~km}$ away) alley of horse chestnuts was collected, and similar amounts were placed evenly in each greenhouse. After mating flights and before the appearance of leaf mines, two randomly selected leaves on each sapling had their petioles permanently marked with tape for subsequent identification when collecting insects.

\section{Material collection}

During the development of the first generation of $C$. ohridella, in successive observations the number of leaves and mines and the moment when the pupal stage appeared were determined. The number of leaves and mines were counted once by an observer. In this period, randomly selected leaflets were collected twice: on the $20^{\text {th }}$ of May and on the $13^{\text {th }}$ of June (resulting in a $2 \times 2 \times 2 \times 3$ design: two dates $\times$ two blocks $\times$ two light conditions $\times$ three saplings). Other leaves (resulting in a $2 \times 2 \times 2 \times 3$ design: two dates $\times$ two blocks $\times$ two light conditions $\times$ three saplings) were collected for determining leaf water content (LWC) and leaf mass per area (LMA). Immediately after collecting the leaves, ten discs from undamaged leaf tissues located between $2^{\text {nd }}$-order leaf veins (omitting the midrib) were excised using a punch. Midrib and secondary leaf veins were not included because only the tissue between these veins is utilised by larvae of $C$. ohridella. Then, the samples were weighed to an accuracy of $\pm 0.01 \mathrm{mg}$ on a semimicro balance (Sartorius CPA225D-0CE, Göttingen, Germany) to obtain the fresh weight (FW). The samples were then ovendried at $65^{\circ} \mathrm{C}$ with air circulation (Memmert $\mathrm{GmbH}+\mathrm{Co} . \mathrm{KG}$, ULE600) to constant weight and then weighed again to obtain the dry weight (DW). Additional leaf samples (ten discs) were prepared for measuring their area and calculating the mean. The fresh discs were scanned (Epson Perfection V700 Photo; 400 dpi, $\sim 250$ pix $\mathrm{mm}^{-2}$ ) and measured using WinFolia 2013 Pro software (Regent Instruments Inc., USA) and the mean area calculated $\left[28.75 \pm 0.04(\mathrm{SE}) \mathrm{mm}^{2}\right]$. LWC and LMA were calculated as follows:

$$
\begin{aligned}
& L W C=1-\frac{D W}{F W} \cdot 100(\%) \\
& L M A=\frac{D W}{28.75 \cdot \text { number of circles }}
\end{aligned}
$$

Between the $21^{\text {st }}$ and $27^{\text {th }}$ of June, C. ohridella pupae were collected. When evidence of the presence of a leaf mine was recorded $(n=66)$, the position of the mine on the leaf was determined. Soon after, the leaf was collected and scanned (Epson Perfection V700 Photo; $200 \mathrm{dpi}, \sim 60$ pix $\mathrm{mm}^{-2}$ ). The areas of the mines were measured using WinFolia 2013 Pro, which facilitated the making of accurate measurements based on the previously determined colour for the background, leaf and leaf mine layers. Five discs from undamaged leaf tissue near to the leaf mines and located between $2^{\text {nd }}$-order leaf veins (not including the midrib) were excised using a punch in order to determine the leaf mass per area (LMA), which was used to calculate the efficiency of converting utilised leaf tissue into the body mass of the leaf miner (ECU). Samples were processed as described above, and equation 2 was used for the calculation of LMA. The pupae were weighed on or the day following that on which they were collected using the previously mentioned semi-micro balance (to $\pm 0.01 \mathrm{mg}$ ). We then calculated utilised leaf mass (ULM, equation 3) and ECU (equation 4):

$$
\begin{aligned}
& U L M=\text { leaf minearea }\left(\mathrm{mm}^{2}\right) \cdot L M A\left(\mathrm{mg} \cdot \mathrm{mm}^{-2}\right) \\
& E C U=\frac{\text { pupa mass }(\mathrm{mg})}{U L M(\mathrm{mg})} \cdot 100(\%)
\end{aligned}
$$

The data collected only allow the calculation of an approximate efficiency of conversion of ingested food (ECI) (Waldbauer, 1968), because $C$. ohridella feed mainly (but not exclusively) on palisade mesophyll (Weryszko-Chmielewska \& Haratym, 2011). Each pupa was observed under a stereomicroscope (Stemi 2000, Göttingen, Germany) in order to select 384 well-developed pupae. Based on the set of characteristics described by Freise \& Heitland (1999) the sex of each individual of $C$. ohridella was determined.

\section{Potential fecundity}

Pupae identified as females were individually placed in plastic vials that were sealed with small pieces of sponge and stored at room temperature and a relative humidity of $75-80 \%$. Within a day of emergence, specimens were frozen and then dissected in Ringer's solution. The ovaries were stained with a $0.5 \%$ solution of Evans blue in Ringer's solution, and the number of vitellogenic and previtellogenic oocytes in the ovaries was counted.

\section{Leaf anatomy}

For anatomical observations, fully developed leaflets were collected from three saplings in each treatment. Squares of $0.5 \times 0.5$ $\mathrm{cm}$ were cut from the middle parts of the lamina. The pieces were fixed in FAA (formalin 5\%, acetic acid 5\%, ethyl alcohol 90\%) for $24 \mathrm{~h}$ at room temperature. After dehydration in a graded series of ethyl alcohol (starting from $70 \%$, followed by $80 \%, 90 \%, 96 \%$, $100 \%$ and butanol), the pieces were embedded in Paraplast (Paraplast Plus, Sigma-Aldrich P3683). Cross-sections (approximately $10 \mu \mathrm{m}$ thick) of these Paraplast blocks were cut using a rotary microtome (Thermo Scientific Rotary Microtome Microm HM 340 E). After mounting on slides, the cross-sections were stained with fast green (Ruzin, 1999), embedded in Euparal (Roth 7356), covered with a cover slip and observed under a light microscope 
(Zeiss Primo Star with attached AxioCam ERc5s camera, Zeiss Göttingen, Germany). Selected objects were photographed.

\section{Chemical analyses}

In the middle of June, one leaf on a long shoot, from each of 24 randomly chosen saplings (resulting in a $2 \times 2 \times 6$ design: two blocks $\times$ two light conditions $\times$ six saplings) was collected for chemical analysis. After removing the petiole, the leaflets of the compound leaves were cut off and oven-dried at $65^{\circ} \mathrm{C}$ with air circulation (Memmert GmbH+Co.KG, ULE600) to constant weight. Oven-drying was done to remove water from plant material. Although, such treatment may influence the measurement of phenolic compounds (described below) sensitive to temperature, previous tests conducted in our laboratory on plant material (leaves) from A. hippocastanum (growing in similar light conditions) did not reveal a significant differences in the content of $\mathrm{TsPh}$ and $\mathrm{OsPh}$ in freeze-dried and oven-dried $\left(40^{\circ} \mathrm{C}\right.$ and $\left.65^{\circ} \mathrm{C}\right)$ material (data not published). Although, it is possible that the temperature affected some of the compounds that were not specifically measured. Leaf mines were individually excised using scissors from each dried leaflet. Then the leaflets were crushed by hand and their midribs removed. This was done to obtain measures of the plant tissues most closely related to those consumed by the leaf miner. Finally, each sample was ground to a fine powder in a ball mill (Retsch ${ }^{\circledR}$ MM200 mixer mill) and stored in closed tubes until analyzed. Carbon and nitrogen contents were determined using an Elemental Combustion System CHNS-O 4010 analyser (Costech Instruments, Italy/USA). Elemental nitrogen content so recorded can be converted into protein content (Yeoh $\&$ Wee, 1994). However, for simplicity we use it as a measure of the content of nitrogen-rich compounds: amino acids, proteins etc. The content of total soluble phenolic compounds ( $\mathrm{TsPh})$ and oxidative capacity $(\mathrm{OsPh})$ in an alkaline environment $(\mathrm{pH} \approx 10)$ were determined as described by Salminen \& Karonen (2011). An acetone/water solution (7/3, v/v) was used for extraction, the aqueous extract was freeze dried, and the residue dissolved in deionised water. Concentrations of $\mathrm{TsPh}$ and $\mathrm{OsPh}$ after oxidation in carbonate-bicarbonate buffer (Sigma Aldrich C3041) were determined using Folin Ciocalteu's Phenol Reagent (Sigma Aldrich F9252), and absorbance was measured at $\lambda=730 \mathrm{~nm}$. The results are expressed in terms of gallic acid (Sigma Aldrich G7384) equivalents.

\section{Statistical analyses}

A one-way ANOVA model was constructed to compare the reduction in percentage photosynthetic photon flux density in the LL and HL treatments. In this analysis, the effect of greenhouse and interaction between greenhouse and light conditions were treated as fixed effects. One-way ANOVA models with mixed effects were conducted to compare the phytochemical measures (carbon, nitrogen, $\mathrm{TsPh}$ and $\mathrm{OsPh}$ contents and nitrogen:carbon ratio) recorded for the plants in the LL and HL treatments (with light as a fixed effect), and greenhouse was included in the model as a random effect. Additional one-way ANOVA models with mixed effects were conducted to compare the LWC and LMA of plants in the LL and HL treatments (with light as a fixed effect), and greenhouse, sapling and collection date as random effects. ANOVA models with mixed effects were conducted to evaluate the effects of light conditions, insect sex and their interaction (fixed effects) on leaf mine area, ULM and ECU. Greenhouse and sapling were included as random effects. These same fixed effects were included in an ANOVA model of pupal mass, and random effects, i.e., leaf nested within sapling, were added. Before all analyses, normal distributions were verified using the ShapiroWilk test. The above mentioned statistical analyses were con- ducted in JMP 13.0 Pro (SAS). A generalised linear model with mixed effects (GLMM) was used for modelling the relationships between potential fecundity (dependent variable) and both light conditions and pupal mass (fixed effects). Greenhouse and sapling were included in this model as random effects. This model was fitted using maximum likelihood (Laplace approximation) and a negative binomial distribution with a $\log$ link function [function glmer.nb (lme4), Bates et al. (2015)]. The full GLMM model was compared with a null model that included only the intercept. The McFadden $\rho^{2}$ was calculated (Domencich \& McFadden, 1975). This index is an alternative to the commonly used coefficient of determination, which cannot be calculated for this GLMM. An analysis of deviance was conducted to test the significance of each fixed factor [Wald $\chi^{2}$ test, function Anova(car), Fox \& Weisberg (2011)]. The GLMM and accompanying analyses were conducted in R 3.4.4 (R Development Core Team, 2018).

\section{RESULTS}

The foil covering the greenhouses reduced the light intensity in the greenhouses to $50 \%( \pm 6 \% \mathrm{SE})$ of that of incident light, and the addition of the mesh reduced it by $78 \%$ $( \pm 4 \% \mathrm{SE})(\mathrm{F}=257 ; \mathrm{df}=1,28 ; \mathrm{P}<0.001)$. Neither greenhouse $(\mathrm{F}=1.04 ; \mathrm{df}=1,28 ; \mathrm{P}=0.32)$ nor light $\times$ greenhouse $(\mathrm{F}=0.05 ; \mathrm{df}=1,28 ; \mathrm{P}=0.83)$ accounted for the variation in the reduction in light intensity at the adopted significance level $(\alpha=0.05)$. Mean diurnal average temperature was lower in low light treatments (LL), by ca. $2^{\circ} \mathrm{C}$, than in high light (HL) treatments, and diurnal temperature range was lower, by ca. $7^{\circ} \mathrm{C}$, in the LL treatments (Table 1).

Leaf anatomy was typical of angiosperms, i.e., the mesophyll was enclosed by an upper and lower epidermis (Fig. 1). The mesophyll was clearly divided into a single layer of palisade parenchyma located close to the upper surface of a leaf and spongy parenchyma close to the lower surface. The leaves of plants in the LL treatments (Fig. 1a) were thinner than those in the HL treatments, and their chlorenchyma cells were smaller (Fig. 1b). In addition, the palisade parenchyma cells of LL leaves (Fig. 1a) were columnar in shape but were not of equal length; therefore, the lower ends of the cells did not form a continuous layer and some of the cells were slightly bent. In the LL treatments, there were gaps between the cells such that many of the horizontal walls at their ends were in contact with internal air spaces. The spongy mesophyll of leaves from the LL treatments typically contained many air cavities (Fig. 1a). The loosely arranged spongy parenchyma cells had approximately circular or oval outlines and were separated by an extensive system of intercellular spaces. Unlike in the LL treatments, the leaves from plants in the HL treatments had a more compact and homogeneous palisade and spongy mesophyll

Table 1. Mean values of diurnal minimum, maximum, average and range of temperatures $\left({ }^{\circ} \mathrm{C}\right)$ recorded in June in the different light treatments in each greenhouse ( $\mathrm{LL}-$ low light, $\mathrm{HL}$ - high light).

\begin{tabular}{lccccc}
\hline & \multicolumn{2}{c}{ Greenhouse \#1 } & & \multicolumn{2}{c}{ Greenhouse \#2 } \\
\cline { 2 - 3 } \cline { 5 - 6 } & $\mathrm{LL}$ & $\mathrm{HL}$ & & $\mathrm{LL}$ & $\mathrm{HL}$ \\
\hline Minimum & 12.5 & 13.0 & & 13.0 & 12.4 \\
Maximum & 30.1 & 37.4 & & 28.4 & 34.7 \\
Mean & 20.3 & 22.2 & & 20.1 & 21.9 \\
Amplitude & 17.7 & 24.4 & & 15.4 & 22.3 \\
\hline
\end{tabular}



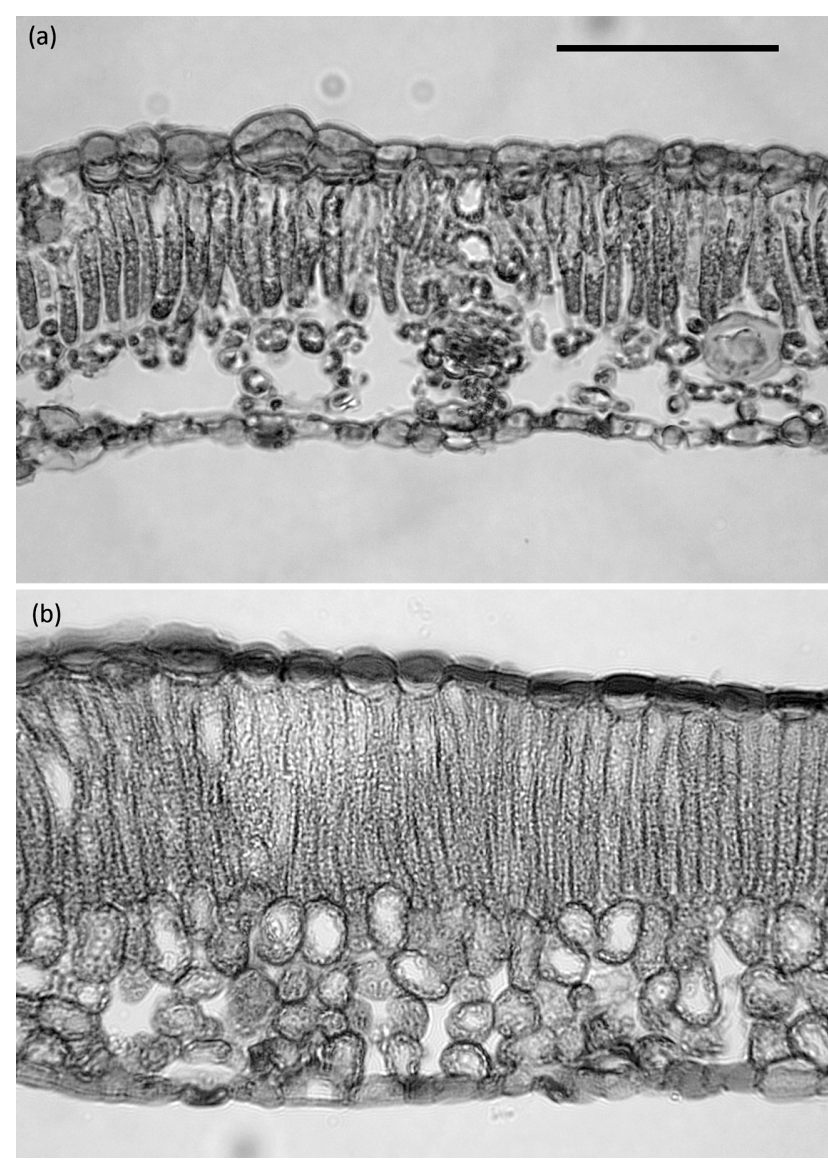

Fig. 1. Cross-sections of leaves from plants growing under low (a$\mathrm{LL})$ and high $(\mathrm{b}-\mathrm{HL})$ light conditions. Bar $=100 \mu \mathrm{m}$.

(Fig. 1b). The columnar palisade mesophyll cells of leaves of plants in the HL treatments adhered to one another better, were more uniform in length and more of them were in contact with spongy parenchyma cells than those of plants in the LL treatments. The cells of the spongy mesophyll of HL leaves were similar in shape to those of LL leaves, but were markedly larger and more densely arranged, with small air spaces between them. Generally, in cross section (Fig. 1), the HL leaves had a more compact structure than the LL leaves.

The eighteen saplings that were grown in both the LL and HL treatments produced, respectively, totals of 308 (mean: $17 \pm 1 \mathrm{SE}$ ) and 288 (mean: 16 \pm 1 SE) leaves. A higher number of leaf mines was recorded for plants in the LL $(n=1493)$ than the HL $(n=900)$ treatments. As a result, the mean number of mines per leaf recorded for the plants in the LL treatments $(4.9 \pm 0.42 \mathrm{SE})$ was higher than that recorded for the plants in the HL treatments $(3.1 \pm 0.31$ $\mathrm{SE})$. Leaves collected from plants growing under LL conditions had lower contents of carbon (Fig. 2a) and greater contents of nitrogen (Fig. 2b) than those of plants grown in HL conditions, and consequently a greater nitrogen:carbon ratio was recorded for those grown in LL conditions ( $\mathrm{F}=$ $12.2 ; \mathrm{df}=1,21 ; \mathrm{P}<0.01)$. The content of secondary metabolites in leaves indicated by the total soluble phenolic compounds $(\mathrm{Ts} P h)$ was greater in those plants grown in HL conditions (Fig. 2c), but light condition did not affect
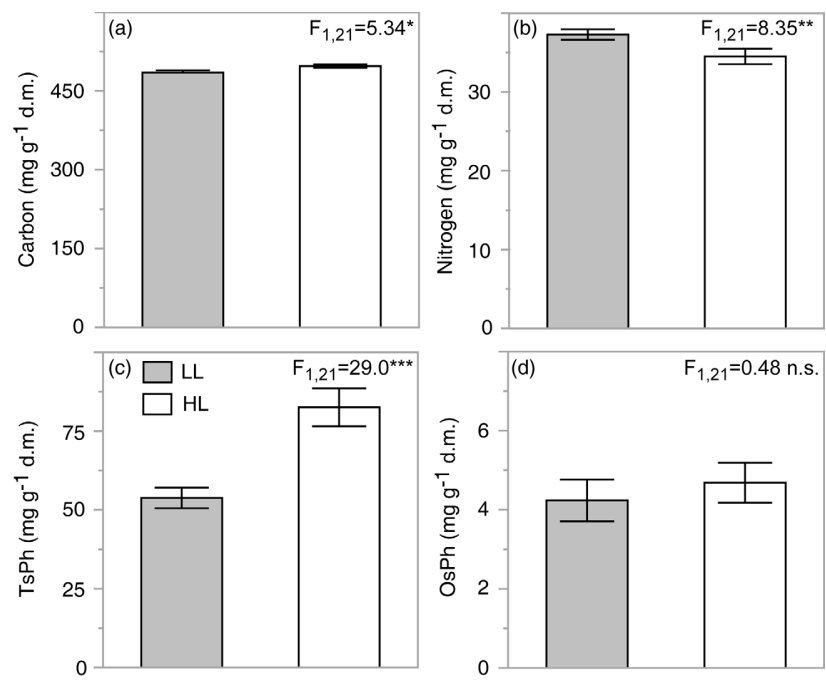

Fig. 2. Mean and standard error of the mean carbon (a), nitrogen (b) and total soluble phenolic compounds (c, gallic acid equivalents) and their oxidative capacity (d, gallic acid equivalents) in dry (d.m.) leaves collected from saplings growing under low (LL) and high $(\mathrm{HL})$ light conditions. ANOVA of the results for the fixed effect of light condition are provided for each column (n.s. $-\mathrm{P}>0.05$, * $\left.\mathrm{P}<0.05,{ }^{* *}-\mathrm{P}<0.01,{ }^{* * *}-\mathrm{P}<0.001\right)$.

the oxidative capacity of the phenolic compounds $(\mathrm{OsPh}$, Fig. 2d). Leaflets collected from plants grown in LL conditions had higher water contents $(68 \% \pm 1 \% \mathrm{SE})$ than those of plants grown in HL conditions $(64 \% \pm 1 \% \mathrm{SE})$, and this was significant $(\mathrm{F}=15.2 ; \mathrm{df}=1,9 ; \mathrm{P}<0.01)$.

Leaf mines on plants grown in LL conditions had a greater average area than those grown in HL conditions (Fig. 3). C. ohridella females damaged greater areas of leaf than

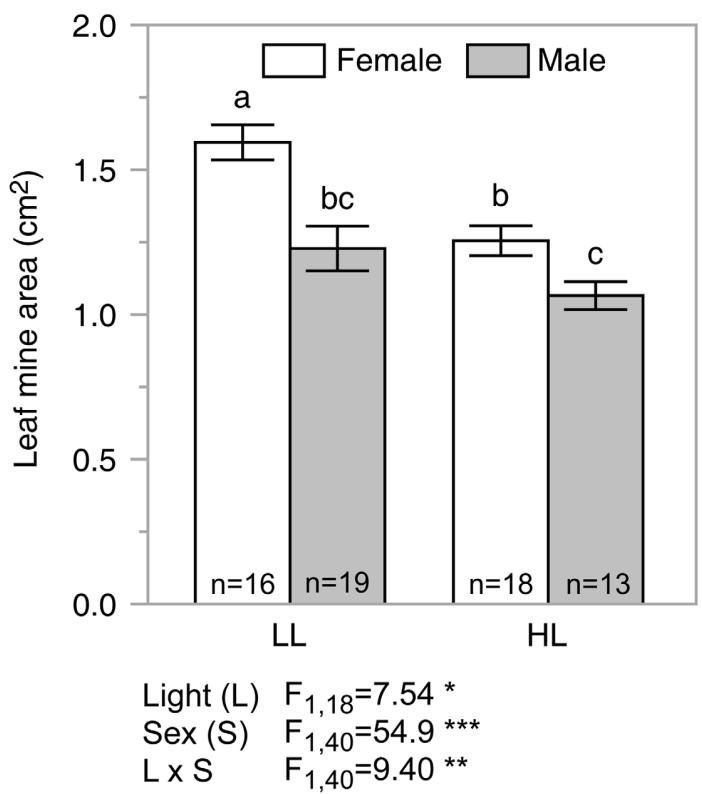

Fig. 3. Mean and standard error of the mean area of the mines produced by males and females in leaves of saplings growing under low (LL) and high (HL) light conditions. On each column, the sample size is presented. ANOVA results for the fixed effects are provided below the columns (n.s. $-\mathrm{P}>0.05$; ${ }^{*}-\mathrm{P}<0.05$; ${ }^{* *}-\mathrm{P}<$ $\left.0.01,{ }^{* * *}-P<0.001\right)$. Mean values with different letters are significantly different (Tukey's HSD test for interaction effect). 


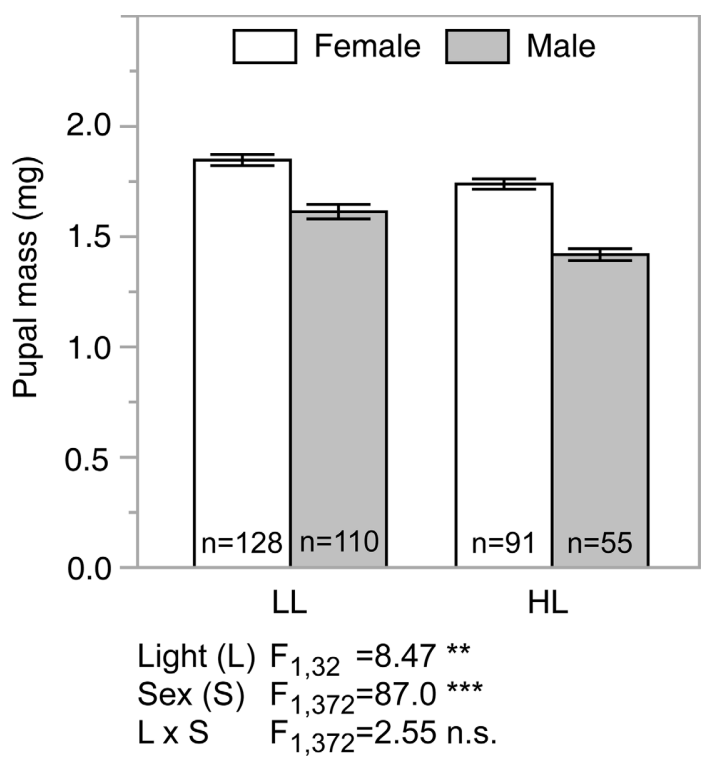

Fig. 4. Mean and standard error of mean mass of male and female pupae collected from saplings growing under low (LL) and high $(\mathrm{HL})$ light conditions. On each column, the sample size is presented. ANOVA results for the fixed effects are provided below the columns (n.s. $\left.-P>0.05 ;{ }^{*}-P<0.05 ;{ }^{* *}-P<0.01,{ }^{* \star}-P<0.001\right)$.

males. However, males feeding on LL plants damaged a similar area of leaf to that of females feeding on HL plants, and the differences in the area of leaves damaged by males in the different light conditions were not significant. The average pupal mass of females was $16 \%$ greater than that of males, and the mass of the pupae collected from saplings growing under $\mathrm{HL}$ conditions was lower than that of those from the LL conditions (Fig. 4). The mean leaf mass per area (LMA) of leaves from plants grown under the LL conditions was lower $\left(3.70 \pm 0.15 \mathrm{SE} \mathrm{mg} \mathrm{cm}{ }^{-2}\right)$ than that of those from the HL conditions $(5.22 \pm 0.22 \mathrm{SE}$ $\left.\mathrm{mg} \mathrm{cm}{ }^{-2}\right)$, and the fixed effect (light) was significant $(\mathrm{F}=$ $38.1 ; \mathrm{df}=1,9 ; \mathrm{P}<0.001)$. Hence, when this was taken into account, the utilised leaf mass (ULM) recorded in the LL $(5.73 \pm 0.26 \mathrm{SE} \mathrm{mg}, \mathrm{n}=35)$ and $\mathrm{HL}$ conditions $(6.87 \pm 0.17$ SE $m g, n=31)$ was similar $(\mathrm{F}=3.72 ; \mathrm{df}=1,15 ; \mathrm{P}=0.07)$ but that ULM differed between the sexes $(\mathrm{F}=53.5, \mathrm{df}=$ 1,44; $\mathrm{P}<0.001)$ : females, $7.09 \pm 0.16 \mathrm{SE} \mathrm{mg}(\mathrm{n}=34)$; males, $5.40 \pm 0.23 \mathrm{SE} \mathrm{mg}(\mathrm{n}=32)$. Taking into account the efficiency of conversion of ingested leaf tissue into body mass (ECU), C. ohridella utilized the leaf tissue of leaves of LL plants more efficiently than that of HL plants, independent of sex (Fig. 5). Females collected from plants grown under LL conditions had the same average potential fecundity (number of vitellogenic and previtellogenic oocytes in their ovaries, $104 \pm 3 \mathrm{SE}, \mathrm{n}=52$ ) as those collected from HL plants (104 $\pm 3 \mathrm{SE}, \mathrm{n}=47)$, and the treatment effect was not statistically significant $\left(\chi^{2}=0.051 ; \mathrm{df}=1 ; \mathrm{P}=\right.$ $0.82)$. This insect trait was not correlated with pupal mass $\left(\chi^{2}=0.584 ; \mathrm{df}=1 ; \mathrm{P}=0.45\right)$. Generally, potential fecundity was weakly associated with treatment and insect mass $\left(\rho^{2}\right.$ $=0.003$ ).

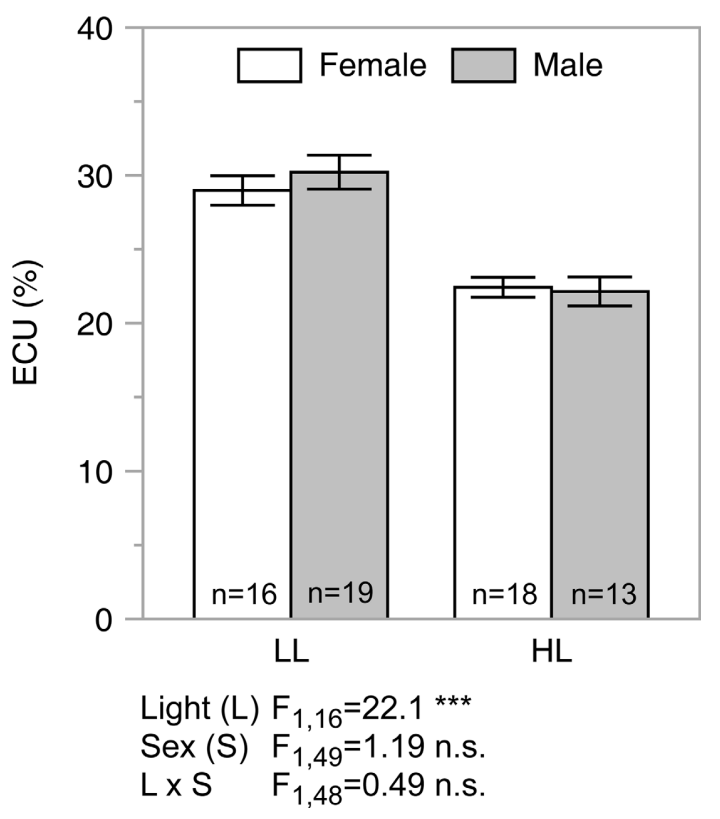

Fig. 5. Mean and standard error of the mean efficiencies for converting leaf tissue into body mass (ECU) for male and female leaf miners collected from saplings growing under low (LL) and high $(\mathrm{HL})$ light conditions. On each column, the sample size is presented. ANOVA results for the fixed effects are provided below the columns (n.s. $-\mathrm{P}>0.05 ;{ }^{*}-\mathrm{P}<0.05 ;{ }^{* *}-\mathrm{P}<0.01,{ }^{* * *}-\mathrm{P}<0.001$ ).

\section{DISCUSSION}

This study revealed the effect of light intensity on the morphology and chemical content of the leaves of A. hippocastanum and how they affect the performance of $C$. ohridella. Of the three insect performance measures analyzed, potential fecundity has the biggest effect on species fitness because it is directly involved in reproduction. Awmack \& Leather (2002) and Karolewski et al. (2017) identify host plant quality as an important determinant of insect fecundity. Hence, the similarity in the potential fecundity of $C$. ohridella in the two light treatments despite the effect these treatment had on leaf composition, which indicates there is no difference in host quality of the plants grown in two treatments for $C$. ohridella. Although a detailed study of the eggs was not done, the potential influences on egg size and quality deserve attention because the availability of amino acids and proteins is a crucial factor influencing food quality (Karlsson \& Van Dyck, 2009) and the content of these compounds differed in the leaves of plants growing in the two treatments. Egg number and egg quality can be independent of female body size (Kiefer et al., 2016). On the other hand, the investment of resources by females into offspring can result in larger insects (García-Barros, 2006). Moreover, an evaluation of prenatal and postnatal effects on offspring body size (Steiger, 2013) reveal that the latter accounts for most of the variation in offspring performance.

Potential fecundity (i.e., number of oocytes in the ovaries) is a trait frequently associated with the dry mass of an insect (Honěk, 1993), with female mass a principal constraint of potential fecundity. Walczak et al. (2017) and Jagiełło et al. (2019), who investigated different host- 
plants and the effect of insecticides, respectively, report such a relationship in $C$. ohridella. However, in their studies, mean pupal mass ( 1.65 and $1.70 \mathrm{mg}$ ) was close to those reported here, the mean number of oocytes was two-fold lower (52 and 40-45). Assuming that the C. ohridella investigated in the two above mentioned studies and the present study (all from Kórnik, Poland) differed little in terms of their genetics, potential fecundity is probably dependent on the rearing conditions. The mean number of oocytes in the present study [104 $\pm 2(\mathrm{SE}), \mathrm{n}=99]$ is similar to that reported for C. ohridella by Girardoz et al. (2007): 107 ( \pm 1 $\mathrm{SE}, \mathrm{n}=314)$. It is possible that these mean values are the maximum for this species (with respect to reported there individuals with greater potential fecundity). A study on Speyeria mormonia Boisduval (Lepidoptera: Nymphalidae) (Boggs \& Freeman, 2005) revealed that its potential fecundity decreases with decrease in body mass, but these authors report that it and realized fecundity is independent of larval feeding. Such independence is consistent with our results.

Body size is an important indicator of insects ecology (Kalinkat et al., 2015). In contrast to the potential fecundity described above, a strong effect of light conditions on the pupal mass of $C$. ohridella was recorded in this study. Specimens collected from plants grown under low light conditions (LL) were heavier than those from high light (HL) conditions. The recorded sexual dimorphism in pupal mass confirms a previous report by Walczak et al. (2017). In most insects, females are much heavier than males, which is mainly due to their reproductive role (Blanckenhorn, 2005; Łukowski et al., 2015). Rhainds (2015) reports a positive correlation between body size and lepidopteran wing length (and hence mobility, and speed of movement) and the largest individuals are more likely to mate and, in effect, have a higher realised fecundity. Host-dependent differences in male size in the melon fly, Zeugodacus cucurbitae Coquillett (Diptera: Tephritidae) are important determinants of its mating pattern (Shelly, 2018). In addition, positive relationships between insect body mass and wing parameters are reported in a study on food quality (under different light conditions and with different host plants) and its effect on the microlepidopteran, Yponomeuta evonymellus L. (Lepidoptera: Yponomeutidae) (Lukowski et al., 2017). On the other hand, research on Orygia spp. (Lepidoptera: Erebidae) (Tammaru et al., 2002) report no relationships between body mass and performance features (pupal mortality, adult longevity, mating success and ovipositional success). The authors of that study emphasize the importance of the positive linear relationship between pupal mass and fecundity when considering the advantages of being larger. Given the similarity in potential fecundity and the large difference in pupal mass in the two light conditions, we cannot infer that light conditions enhance $C$. ohridella performance.

On the basis of our results, it is not possible to identify one factor that directly affects food quality for C. ohridella. From a macroecological point of view, variation in body size in insects depends on many external and internal factors (Chown \& Gaston, 2010). At the microecological scale, Davidowitz et al. (2004) report that peak larval mass decreases with increase in temperature and decrease in food quality. In the present study, both chemicals in the leaves (content of carbon, nitrogen and sum of soluble phenolics) and abiotic conditions (temperature, light) were experimentally manipulated. Nitrogen is present in plant organic compounds, i.e. amino acids, proteins etc. Such compounds are important components in animal diets. The concentrations of nitrogen in plant tissues are strongly correlated with ECI, the efficiency of converting ingested food into body mass (Mattson, 1980). That C. ohridella collected from plants grown under LL conditions (in which there were greater contents of nitrogen) had higher conversion efficiencies of the utilised leaf mass (ECU) than those collected from HL plants, is consistent with the above. A similar effect of light conditions on ECI is reported by Mąderek et al. (2015). However, they report that Gonioctena quinquepunctata F. (Coleoptera: Chrysomelidae) compensate for low diet quality by increasing food consumption. That is in contrast to our results, which indicate that utilised leaf mass (ULM) was similar in the two light conditions. Strong evidence for a dominant role of high nitrogen content in improving the performance of $C$. ohridella in our study is provided by Cornelissen \& Stiling (2006). They manipulated the nitrogen content of leaves by applying fertilizer and report that Acrocercops albinatella Chambers (Lepidoptera: Gracillariidae) and Brachys tesselatus F. (Coleoptera: Buprestidae) produce smaller leaf mines and develop faster when the leaf nitrogen content is high.

The potential role of phenolic compounds in the defence against $C$. ohridella in different light conditions was considered in the present study. Two measures were evaluated: total soluble phenolics content $(\mathrm{TsPh})$ and their oxidative capacity (OsPh) in an alkaline environment. As we expected, there was more $\mathrm{TsPh}$ in leaves of plants grown under HL conditions. This measure is a good indicator of the influence of visible light intensity and UV radiation (Younis et al., 2010). It does not, however, imply that it strongly influences biotic factors, as emphasised in a review by Karabourniotis et al. (2014). Hence, we measured OsPh, as proposed by Salminen \& Karonen (2011), to investigate the potential repellent role of the phenolic compounds in the leaves of $A$. hippocastanum. It is widely assumed that the $\mathrm{pH}$ of the gut of lepidopterans is close to alkaline (Terra et al., 1996). A study by Stygar et al. (2010) report a similar optimum $\mathrm{pH}$ for the gut enzymes of $C$. ohridella and other lepidopterans. We recorded low levels of $\mathrm{OsPh}$ in the leaves of $A$. hippocastanum in our study (Fig. 2d), which may indicate low levels of ellagitannins (Barbehenn et al., 2006a). In a study of Acer saccharum Marshall and Quercus rubra L., Barbehenn et al. (2006b) report that condensed tannins have an antioxidant effect on the oxidative activity of hydrolysable tannins. The high amounts of condensed tannins in the leaves of $A$. hippocastanum (Oszmiański et al., 2014; Jagiełło et al., 2017) might not be effective against insect herbivores (Barbehenn \& Con- 
stabel, 2011). The localisation of potentially anti-herbivore phenolic compounds within a leaf is very important (Karabourniotis et al., 2014). Most probably tannins with a high oxidative capacity occur in the leaf mesophyll-tissue consumed by the leaf miner studied (Karabourniotis et al., 2014). However, the very small difference in the level of $\mathrm{OsPh}$ in the leaves of plants grown under different light conditions and the overall low concentrations lead use to deduce that the phenolic compounds in the leaves of $A$. hippocastanum do not repel lepidopterans, regardless of the effect of different light conditions.

\section{CONCLUSIONS}

The different light conditions used in this study substantially affected the morphology and chemistry of the leaves of the saplings grown under these conditions. As a result of a low photosynthetic photon flux density (PPFD), leaves developed less compact mesophyll and had a lower leaf mass per area, greater contents of nitrogen and water and a lower content of total soluble phenolic compounds. The difference in the treatments led us to predict a higher food quality when PPFD is limited, which was confirmed by higher pupal masses and efficiencies of utilization of leaf tissue. However, potential fecundity did not differ in the two treatments used, which were a 50 and $80 \%$ reduction in outdoor PPFD, which led us to speculate about the performance parameter that has the greatest effect on insect fitness. Potential fecundity is directly linked to potential reproduction, and reproduction is the most important biological process for gene propagation and the persistence of a species. On the other hand, pupal mass correlates positively with many other insect characteristics that influence the probability of mating. Based on our results, we cannot conclude which of the light conditions was the most favourable for the development of $C$. ohridella, but based on the evidence it is most likely the low light conditions. The low oxidative capacity of phenolic compounds in the leaf tissues of $A$. hippocastanum may be one of several factors that determined the success of $C$. ohridella.

FUNDING. This research was financially supported by the National Science Centre, Poland (grant no. 2012/07/B/NZ9/01315) and statutory funding from the Institute of Dendrology (Polish Academy of Sciences).

AUTHOR CONTRIBUTIONS. MJG received financial support; MJG \& RJ designed the study; AŁ, MJG \& RJ collected material; MG analyzed leaf anatomy; RJ prepared the draft manuscript; and all authors contributed to the development of the manuscript.

ACKNOWLEDGEMENTS. We are indebted to U. Walczak from Adam Mickiewicz University for help with the collection and processing of the plant material, especially the determination of the potential fecundity of $C$. ohridella. We thank the anonymous reviewers for their insightful comments and suggestions.

\section{REFERENCES}

Awmack C.S. \& Leather S.R. 2002: Host plant quality and fecundity in herbivorous insects. - Annu. Rev. Entomol. 47: 817-844.
Barbehenn R.V. \& Constabel C.P. 2011: Tannins in plant-herbivore interactions. - Phytochemistry 72: 1551-1565.

Barbehenn R.V., Jones C.P., Hagerman A.E., Karonen M. \& SALMINEN J.-P. 2006a: Ellagitannins have greater oxidative activities than condensed tannins and galloyl glucoses at high pH: potential impact on caterpillars. - J. Chem. Ecol. 32: 2253-2267.

Barbehenn R.V., Jones C.P., Karonen M. \& Salminen J.-P. 2006b: Tannin composition affects the oxidative activities of tree leaves. - J. Chem. Ecol. 32: 2235-2251.

Bates D., Mächler M., Bolker B. \& Walker S. 2015: Fitting linear mixed-effects models using lme4. - J. Stat. Softw. 67: $1-48$.

Bidart-Bouzat M.G. \& Imeh-Nathaniel A. 2008: Global change effects on plant chemical defenses against insect herbivores. J. Integr. Plant Biol. 50: 1339-1354.

Birner A. \& Bohlander F. 2004: Mine development of horse chestnut leaf-miner (Cameraria ohridella) on leafs exposed to sunlight or shade. In Kalinova B. (ed.): 1st International Cameraria Symposium. Cameraria ohridella and Other Invasive Leaf-Miners in Europe, Prague, Czech Republic, March 24-27, 2004. Institute of Organic Chemistry and Biochemistry ASCR, Prague, p. 5.

BLANCKENHORN W.U. 2005: Behavioral causes and consequences of sexual size dimorphism. - Ethology 111: 977-1016.

Boggs C.L. \& FreEman K.D. 2005: Larval food limitation in butterflies: effects on adult resource allocation and fitness. - Oecologia 144: 353-361.

Cheong D.H.J., Arfuso F., Sethi G., Wang L., Hui K.M., Kumar A.P. \& TRAn T. 2018: Molecular targets and anti-cancer potential of escin. - Cancer Lett. 422: 1-8.

Chown S.L. \& Gaston K.J. 2010: Body size variation in insects: a macroecological perspective. - Biol. Rev. 85: 139-169.

ConNOR E.F. 2006: Effects of the light environment on oviposition preference and survival of a leaf-mining moth, Cameraria hamadryadella (Lepidoptera: Gracillariidae), on Quercus alba L. - Ecol. Entomol. 31: 179-184.

CONNOR E.F. \& TAVERNER M.P. 1997: The evolution and adaptive significance of the leaf-mining habit. - Oikos 79: 6-25.

Cornelissen T. \& Stiling P. 2006: Does low nutritional quality act as a plant defence? An experimental test of the slow-growth, high-mortality hypothesis. - Ecol. Entomol. 31: 32-40.

D'Costa L., Koricheva J., Straw N. \& Simmonds M.S.J. 2013: Oviposition patterns and larval damage by the invasive horsechestnut leaf miner Cameraria ohridella on different species of Aesculus. - Ecol. Entomol. 38: 456-462.

D'Costa L., Simmonds M.S.J., Straw N., Castagneyrol B. \& KoricheVA J. 2014: Leaf traits influencing oviposition preference and larval performance of Cameraria ohridella on native and novel host plants. - Entomol. Exp. Appl. 152: 157-164.

Davidowitz G., D'Amico L.J. \& Nijhout H.F. 2004: The effects of environmental variation on a mechanism that controls insect body size. - Evol. Ecol. Res. 6: 49-62.

DeschKa G. 1993: Die Miniermotte Cameraria ohridella Deschka \& Dimic eine Gefahr für die Roßkastanie Aesculus hippocastanum L. (Insecta, Lepidoptera, Lithocolletidae). - Linzer Biol. Beitr. 25: 141-148.

Deschka G. \& Dimić N. 1986: Cameraria ohridella sp. n. (Lep., Lithocolletidae) aus Mazedonien, Jugoslawien. - Acta Entomol. Jugoslav. 22: 11-23.

Domencich T.A. \& McFAdDEN D. 1975: Statistical estimation of choice probability functions. In Jorgenson D.W. \& Waelbroeck J. (eds): Urban Travel Demand. A Behavioral Analysis. NorthHolland Publishing Company, New York, pp. 101-125. 
European COMMISSION 2018: Commission Implementing Regulation (EU) 2018/783. URL: https://eur-lex.europa.eu/eli/reg impl/2018/783/oj.

FEeny P. 1970: Seasonal changes in oak leaf tannins and nutrients as a cause of spring feeding by winter moth caterpillars. Ecology 51: 565-581.

Ferracini C. \& Alma A. 2007: Evaluation of the community of native eulophid parasitoids on Cameraria ohridella Deschka and Dimic in urban areas. - Environ. Entomol. 36: 1147-1153.

Ferracini C. \& Alma A. 2008: How to preserve horse chestnut trees from Cameraria ohridella in the urban environment. Crop Prot. 27: 1251-1255.

Ferracini C., Curir P., Dolci M., Lanzotti V. \& Alma A. 2010 Aesculus pavia foliar saponins: defensive role against the leafminer Cameraria ohridella. - Pest Manag. Sci. 66: 767772.

Fox J. \& Weisberg S. 2011: An R Companion to Applied Regression. Sage, Thousand Oaks, CA, $472 \mathrm{pp}$.

Freise J. \& Heitland W. 1999: A brief note on sexual differences in pupae of the horse-chestnut leaf miner, Cameraria ohridella Deschka \& Dimic (1986) (Lep., Gracillariidae), a new pest in Central Europe on Aesculus hippocastanum. - J. Appl. Entomol. 123: 191-192.

Fujimura T., Tsukahara K., Moriwaki S., Hotta M., Kitahara T. \& TAKEMA Y. 2006: A horse chestnut extract, which induces contraction forces in fibroblasts, is a potent anti-aging ingredient. - J. Cosmet. Sci. 57: 369-376.

Galway K.E., Duncan R.P., Syrett P., Emberson R.M. \& ShepPARD A.W. 2004: Insect performance and host-plant stress: a review from a biological control perspective. In Cullen J.M., Briese D.T., Kriticos D.J., Lonsdale W.M., Morin L. \& Scott J.K. (eds): Proceedings of the XI International Biological Control of Weeds Symposium, Canberra, Australia, April 27-May 2, 2003. CSIRO Entomology, Canberra, pp. 394-399.

García-BARros E. 2006: Within and between species scaling in the weight, water, carbon and nitrogen contents of eggs and neonate larvae of twelve satyrine butterflies (Lepidoptera: Nymphalidae). - Eur. J. Entomol. 103: 559-568.

Girardoz S., Quicke D.L.J. \& Kenis M. 2007: Factors favouring the development and maintenance of outbreaks in an invasive leaf miner Cameraria ohridella (Lepidoptera: Gracillariidae): a life table study. - Agric. For. Entomol. 9: 141-158.

Gninenko Y.I., Muhamadiev N.S. \& Ashikbaev N.Z. 2017: Cameraria ohridella: the first record in Central Asia. - Russ. J. Biol. Invas. 8: 10-13.

GwiazDowicz D.J. \& WiśNIEWSKI J. 2011: Aesthetic values of plant cover. In Gwiazdowicz D.J. \& Wiśniewski J. (eds): Forest Aesthetics. Ośrodek Kultury Leśnej, Gołuchów, pp. 81-219 [in Polish with English abstr.].

Hering E.M. 1951: Mine producers. In Hering E.M. (ed.): Biology of the Leaf Miners. Springer, Dordrecht, pp. 39-53.

HoNĚK A. 1993: Intraspecific variation in body size and fecundity in insects: a general relationship. — Oikos 66: 483-492.

Jagiello R., Baraniak E., Karolewski P., ŁaKomy P., BehnKeBorowczyk J., WalczaK U. \& Giertych M.J. 2017: Ecophysiological aspects of the interaction between Cameraria ohridella and Guignardia aesculi on Aesculus hippocastanum. —Dendrobiology 78: 146-156.

JagielŁo R., Walczak U., Iszkuto G., Karolewski P., Baraniak E. \& GierTYCh M.J. 2019: Impact of Cameraria ohridella on Aesculus hippocastanum growth and long-term effects of trunk injection with pesticides. - Int. J. Pest Manag. 65: 33-43.

Kalinkat G., Jochum M., Brose U. \& Dell A.I. 2015: Body size and the behavioral ecology of insects: linking individuals to ecological communities. - Curr. Opin. Insect Sci. 9: 24-30.
Karabourniotis G., Liakopoulos G., Nikolopoulos D., Bresta P., Stavroulaki V. \& Sumbele S. 2014: "Carbon gain vs. water saving, growth vs. defence": Two dilemmas with soluble phenolics as a joker. - Plant Sci. 227: 21-27.

Karlsson B. \& VAN Dyck H. 2009: Evolutionary ecology of butterfly fecundity. In Settele J., Shreeve T., Konvička M. \& Van Dyck H. (eds): Ecology of Butterflies in Europe. Cambridge University Press, Cambridge, pp. 189-197.

Karolewski P., Łukowski A., Walczak U., Baraniak E., Mucha J. \& GieRTYCH M.J. 2017: Larval food affects oviposition preference, female fecundity and offspring survival in Yponomeuta evonymellus. - Ecol. Entomol. 42: 657-667.

KeHRLi P. \& BACHeR S. 2003: Date of leaf litter removal to prevent emergence of Cameraria ohridella in the following spring. Entomol. Exp. Appl. 107: 159-162.

Kenis M., Tomov R., Svatos A., Schlinsog P., Vaamonde C.L., Heitland W., Grabenweger G., Girardoz S., Freise J. \& AvtZIS N. 2005: The horse-chestnut leaf miner in Europe - prospects and constraints for biological control. In Hoddle M.S. (ed.): Proceedings of the Second International Symposium on Biological Control of Arthropods, Davos, Switzerland, September 12-16, 2005. USDA Forest Service, Morgantown, WV, pp. 77-90.

Kiefer D., Warburton E.M., KhoKhlova I.S. \& Krasnov B.R. 2016: Reproductive consequences of female size in haematophagous ectoparasites. - J. Exp. Biol. 219: 2368-2376.

Koricheva J. 2002: Meta-analysis of sources of variation in fitness costs of plant antiherbivore defenses. - Ecology 83: 176-190.

KulBat K. 2016: The role of phenolic compounds in plant resistance. - Biotechnol. Food Sci. 80: 97-108.

Lambers H., Chapin III F.S. \& Pons T.L. 2008: Photosynthesis. In Lambers H., Chapin III F.S. \& Pons T.L. (eds): Plant Physiological Ecology. Springer, New York, pp. 11-99.

Li J., Ou-Lee T.-M., Raba R., Amundson R.G. \& Last R.L. 1993: Arabidopsis flavonoid mutants are hypersensitive to UV-B irradiation. - Plant Cell 5: 171-179.

ŁuKowski A., Mąderek E., GierTych M.J. \& Karolewski P. 2015: Sex ratio and body mass of adult herbivorous beetles depend on time of occurrence and light conditions. - PLOS ONE 10(12): e0144718, 18 pp.

Łukowski A., Giertych M.J., Walczak U., Baraniak E. \& KaROLEWSKI P. 2017: Light conditions affect the performance of Yponomeuta evonymellus on its native host Prunus padus and the alien Prunus serotina. — Bull. Entomol. Res. 107: 208-216.

MąDerek E., Łukowski A., Giertych M.J. \& Karolewski P. 2015: Influence of native and alien Prunus species and light conditions on performance of the leaf beetle Gonioctena quinquepunctata. - Entomol. Exp. Appl. 155: 193-205.

MATTSON W.J. 1980: Herbivory in relation to plant nitrogen content. - Annu. Rev. Ecol. Syst. 11: 119-161.

Oszmiański J., Kalisz S. \& WoJdyŁo A. 2014: The content of phenolic compounds in leaf tissues of white (Aesculus hippocastanum L.) and red horse chestnut (Aesculus carea H.) colonized by the horse chestnut leaf miner (Cameraria ohridella Deschka \& Dimić). - Molecules 19: 14625-14636.

Percival G.C., Banks J. \& Keary I. 2012: Evaluation of organic, synthetic and physical insecticides for the control of horse chestnut leaf miner (Cameraria ohridella). - Urban For. Urban Green. 11: 426-431.

Péré C., Augustin S., Turlings T.C.J. \& Kenis M. 2010: The invasive alien leaf miner Cameraria ohridella and the native tree Acer pseudoplatanus: a fatal attraction? - Agric. For. Entomol. 12: 151-159. 
Poorter H., NiInemets Ü., Poorter L., Wright I.J. \& Villar R. 2009: Causes and consequences of variation in leaf mass per area (LMA): a meta-analysis. — New Phytol. 182: 565-588.

R Development Core Team 2018: R: A Language and Environment for Statistical Computing. R Fundation for Statistical Computing, Vienna. URL: http://www.R-project.org.

Rämert B., Kenis M., Kärnestam E., Nyström M. \& RänNBäcK L.-M. 2011: Host plant suitability, population dynamics and parasitoids of the horse chestnut leafminer Cameraria ohridella (Lepidoptera: Gracillariidae) in southern Sweden. - Acta Agric. Scand. (B) 61: 480-486.

Ravazzi C. \& Caudullo G. 2016: Aesculus hippocastanum in Europe: distribution, habitat, usage and threats. In San-MiguelAyanz J., de Rigo D., Caudullo G., Houston Durrant T. \& Mauri A. (eds): European Atlas of Forest Tree Species. Publication Office of the European Union, Luxemburg, p. 60.

RHAINDS M. 2015: Size-dependent realized fecundity in two lepidopteran capital breeders. - Environ. Entomol. 44: 11931200.

RuzIN S.E. 1999: Plant Microtechnique and Microscopy. Oxford University Press, Oxford, New York, 322 pp.

Salminen J.-P. \& Karonen M. 2011: Chemical ecology of tannins and other phenolics: we need a change in approach. - Funct. Ecol. 25: 325-338.

SIRTORI C.R. 2001: Aescin: pharmacology, pharmacokinetics and therapeutic profile. - Pharmacol. Res. 44: 183-193.

ŠEFrovÁ H. \& LaŠTŮVKa Z. 2001: Dispersal of the horse-chestnut leafminer, Cameraria ohridella Deschka \& Dimić, 1986, in Europe: its course, ways and causes (Lepidoptera: Gracillariidae). - Entomol. Z. 111: 194-198.

Schoonhoven L.M., van LoOn J.J.A. \& Dicke M. 2012: Plants as insect food: not the ideal. In Schoonhoven L.M., van Loon J.J.A., Dicke M. (eds): Insect-Plant Biology. Oxford University Press, New York, pp. 99-134.

SHELLY T.E. 2018: Larval host plant influences male body size and mating success in a tephritid fruit fly. - Entomol. Exp. Appl. 166: $41-52$

SinClair R.J. \& Hughes L. 2010: Leaf miners: The hidden herbivores. - Austral Ecol. 35: 300-313.

STEIGER S. 2013: Bigger mothers are better mothers: Disentangling size-related prenatal and postnatal maternal effects. Proc. R. Soc. (B) 280: 20131225, 9 pp.
Stygar D., Dolezych B., Nakonieczny M., Migula P., MichalcZYK K. \& ZAAK M. 2010: Digestive enzymes activity in larvae of Cameraria ohridella (Lepidoptera: Gracillariidae). $-C . R$. Biol. 333: 725-735.

TAmmaru T., Esperk T. \& CAstellanos I. 2002: No evidence for costs of being large in females of Orgyia spp. (Lepidoptera, Lymantriidae): larger is always better. - Oecologia 133: 430 438.

Tarwacki G., Bystrowski C. \& Celmer-Warda K. 2012: Effect of sun-exposure of the horse chestnut (Aesculus hippocastanum L.) on the occurrence and number of parasitoids of the horse chestnut leafminer (Cameraria ohridella Deschka \& Dimic) in central Poland in 2004-2006. - Folia For. Pol. (A) 54: 56-62.

Terra W.R., Ferreira C. \& BaKer J.E. 1996: Compartmentalization of digestion. In Lehane M.J. \& Billingsley P.F. (eds): Biology of the Insect Midgut. Chapman \& Hall, London, pp. 206-235.

Volter L. \& Kenis M. 2006: Parasitoid complex and parasitism rates of the horse chestnut leafminer, Cameraria ohridella (Lepidoptera: Gracillariidae) in the Czech Republic, Slovakia and Slovenia. - Eur. J. Entomol. 103: 365-370.

WalcZaK U., BaraniaK E. \& ZduniaK P. 2017: Survival, body mass and potential fecundity of the invasive moth Cameraria ohridella (Lepidoptera: Gracillariidae) on its original host plant Aesculus hippocastanum and Aesculus glabra. - Eur. J. Entomol. 114: 295-300.

WALDBAUER G.P. 1968: The consumption and utilization of food by insects. - Adv. Insect Phys. 5: 229-288.

Weryszko-Chmielewska E. \& Haratym W. 2011: Changes in leaf tissues of common horse chestnut (Aesculus hippocastanum L.) colonised by the horse-chestnut leaf miner (Cameraria ochridella Deschka \& Dimić). - Acta Agrobot. 64(4): 11-22.

Yеон H.-H. \& WeE Y.-C. 1994: Leaf protein contents and nitrogen-to-protein conversion factors for 90 plant species. - Food Chem. 49: 245-250.

Younis M.E.-B., Hasaneen M.N.A.-G. \& Abdel-Aziz H.M.M. 2010: An enhancing effect of visible light and UV radiation on phenolic compounds and various antioxidants in broad bean seedlings. - Plant Signal. Behav. 5: 1197-1203.

Received October 5, 2018; revised and accepted January 11, 2019 Published online February 5, 2019 